\title{
Tetrabutylphosphonium 4-ethoxyvalerate as a biomass-originated media for homogeneous palladium-catalyzed Hiyama coupling reactions
}

\author{
László Orha ${ }^{1,2}$ - Ábrahám Papp ${ }^{1}$ József M. Tukacs ${ }^{1}$ - László Kollár ${ }^{3}$ - László T. Mika1 (1)
}

Received: 23 May 2020 / Accepted: 13 July 2020 / Published online: 23 July 2020

(c) The Author(s) 2020

\begin{abstract}
The introduction of a biomass-derived ionic liquid into the Hiyama coupling reactions, which has been considered as a powerful tool for the synthesis of symmetrically and non-symmetrically substituted biaryl structures, could further control or even reduce the environmental impact of this transformation. It was shown that tetrabutylphosphonium 4-ethoxyvalerate, a $\gamma$-valerolactone-based ionic liquid, can be utilized as an alternative solvent to create carbon-carbon bonds between aryl iodides and functionalized organosilanes in the presence of $1 \mathrm{~mol} \% \mathrm{Pd}$ under typical Hiyama conditions $\left(130^{\circ} \mathrm{C}, 24 \mathrm{~h}\right.$, tetrabutylammonium fluoride activator). A comparison of different ionic liquids was performed, and the effects of the catalyst precursor and the moisture content of the reaction mixture on the activity of the catalyst system were investigated. The functional group tolerance was also studied, resulting in 15 cross-coupling products (3a-o) with isolated yields of 45-72\% and excellent purity $(>98 \%)$.
\end{abstract}

Keywords Hiyama coupling · Ionic liquids · Homogeneous catalysis · Green chemistry

\section{Introduction}

The transition-metal-catalyzed cross-coupling reactions have emerged as one of the most powerful tools for the creative construction of both $\mathrm{C}-\mathrm{C}$ and $\mathrm{C}-\mathrm{X}$ (X: heteroatom) bonds, especially in multistep synthesis of biologically active compounds (Yang et al. 2017; Shi et al. 2011; Hosseinian et al. 2018; Jana et al. 2011). From the series of typically applied $\mathrm{d}^{10}$ metals, the palladium-catalyzed transformations have

Electronic supplementary material The online version of this article (https://doi.org/10.1007/s11696-020-01287-y) contains supplementary material, which is available to authorized users.

László T. Mika

laszlo.t.mika@mail.bme.hu

1 Department of Chemical and Environmental Process Engineering, Budapest University of Technology and Economics, Múegyetem rkp. 3, Budapest 1111, Hungary

2 Institute of Isotopes, Konkoly-Thege Miklós str. 29-33, Budapest 1121, Hungary

3 Department of Inorganic Chemistry, University of Pécs and János Szentágothai Research Center and MTA-PTE Research Group for Selective Chemical Synthesis, Ifjúság u. 6, Pécs 7624, Hungary received outstanding interest, due to their excellent chemoselectivity, functional group tolerance, and mild operation conditions, which are of great importance in the synthesis of pharmaceuticals and agrochemicals (Devendar et al. 2018; Johansson Seechurn et al. 2012; Biajoli et al. 2014; González-Sebastián and Morales-Morales 2019). Among these reactions, the Hiyama coupling represents an excellent protocol for the synthesis of symmetrically and nonsymmetrically substituted biaryl structures via coupling of corresponding aryl halides and organosilanes (Hatanaka and Hiyama 1988; Sore et al. 2012; Nakao and Hiyama 2011). The latter, as transmetalation reagents exhibit several advantages over organoboranes or organostannanes, such as low cost, low toxicity, ready availability, and high chemical stability. The protocol exhibits high regio- and stereochemistry, as well (Horn 1995; Nakao and Hiyama 2011). The silicon waste of the reaction can easily be incinerated to harmless $\mathrm{SiO}_{2}$. All of these points have made the Hiyama coupling an environmentally attractive method; however, it had received limited attention in comparison with Heck, Sonogashira, or Suzuki reaction, before the improved synthetic approaches towards novel organosilane compounds renewed its importance (Denmark and Regens 2008; Denmark and Liu 2010). Depending on the structure and/or nature of organosilanes, 
i.e., vinyl silanes (Wolf and Lerebours 2004), alkoxysilanes, silanols (Hirabayashi et al. 1999), and silanolates (Denmark et al. 2008), a huge variety of application scope can be drawn including representation of a key step in the total synthesis of complex structures, for example, the total synthesis of (+)-brasilenyne (Denmark and Yang 2004) and of (+)-papulacandin D (Denmark et al. 2007).

Despite these advantages, the Hiyama couplings are usually performed in common organic solvents, which usually have high toxicity, flammability, and vapor pressure even at low temperatures resulting in serious environmental concerns. As reported by U.S. FDA guidelines (CDER 2017), the commonly used solvents for the Hiyama reactions such as tetrahydrofuran (Miller and Montgomery 2014; Cheng et al. 2013), dioxane (Zhang et al. 2014), N,N-dimethylformamide (Handy et al. 2005), toluene (Denmark et al. 2008), and 1,2-dichloroethane (Ramgren and Garg 2014) are classified into Class 1 and 2, which utilizations should be avoided or limited, respectively, particularly in the pharmaceutical industry. To eliminate these hazardous auxiliary materials, the reactions have been demonstrated in alternative media, e.g., water (Sakon et al. 2017; Inés et al. 2011; Wolf and Lerebours 2004) or glycerol (Marset et al. 2018). Although, numerous Pd-catalyzed coupling reactions such as Suzuki, Sonogashira, Heck, and Stille were demonstrated in ionic liquids (ILs) (Li et al. 2018; Prechtl et al. 2010; Hallett and Welton 2011), which have been utilized as versatile and easily tunable alternative reaction media, and only a few studies were published on the Hiyama reaction (Mandal et al. 2019). First, Slattery and co-workers demonstrated the applicability of 1-pentyl-1-methylpyrrolidinium bis(trifluoromethylsulfonyl)imide $\left(\left[\mathrm{C}_{5} \mathrm{MPyrr}\right]\left[\mathrm{Tf}_{2} \mathrm{~N}\right]\right)$ as a reaction media for allyl-aryl coupling under mild conditions (Bäuerlein et al. 2009). Jain developed a phosphane-free protocol for the manufacture of functionalized biaryls with good to excellent yields in 3-(3-cyanopropyl)-1-methyl-1H-imidazol-3-ium hexafluorophosphate ([CN-bmim] $\left.\left[\mathrm{PF}_{6}\right]\right)$ by the use of in situ generated Pd nanoparticles (Premi and Jain 2013). The effect of the ILs on the stabilization of Pd nanoparticles was also shown. However, acceptable isolated yields were achieved in the presence of a common co-solvent (Planellas et al. 2014).

Although Hiyama coupling is a well-known transformation, according to the best of our knowledge, it has not been carried out in biomass-originated ILs, which could additionally act as a ligand. Therefore, by the introduction of a biomass-based solvent into this synthetically important reaction, the environmental impacts of a Hiyama reaction involved synthesis could be further controlled and reduced.

Herein, we report a study on the palladium-catalyzed Hiyama coupling reactions to synthesize various biaryl structures in biomass-originated $\gamma$-valerolactone-based ionic liquid tetrabutylphosphonium 4-ethoxyvalerate ([TBP] [4EtOV]) extending its utilization for catalysis.

\section{Experimental}

\section{Materials and equipment}

The sources of chemicals are listed in the Supplementary Material. The $\gamma$-valerolactone-based ionic liquids were prepared by a published method with details presented in Supplementary Material.

The NMR spectra were recorded on a Brucker Avance $250 \mathrm{MHz}$ spectrometer. Water contents of the ionic liquids were determined by Karl Fischer titration performed by HANNA Instruments 904. GC analyses were performed on an Agilent $6890 \mathrm{~N}$ instrument with HP-Innowax capillary column $(15 \mathrm{~m} \times 0.25 \mu \mathrm{m} \times 0.25 \mu \mathrm{m})$ using $\mathrm{H}_{2}$ as a carrier gas.

\section{General procedure for Hiyama coupling reactions}

In a $4 \mathrm{~mL}$ screw-cap vial, $0.5 \mathrm{mmol}$ of the corresponding iodoarene compounds, 1.5 eq of the corresponding silane, 1.5 eq of tetrabutylammonium fluoride (TBAF), $0.01 \mathrm{eq}$ $\mathrm{PdCl}_{2}\left(\mathrm{PPh}_{3}\right)_{2}$, and $0.8 \mathrm{~mL}$ of tetrabutylphosphonium 4-ethoxyvalerate ([TBP][4EtOV]) ionic liquid were mixed and stirred at $130{ }^{\circ} \mathrm{C}$ for $24 \mathrm{~h}$. After cooling, the mixture was partitioned between $5 \mathrm{~mL}$ of $1 \mathrm{M} \mathrm{HCl}$ and $5 \mathrm{~mL}$ of pentane. The aqueous phase was extracted subsequently with $3 \times 5 \mathrm{~mL}$ of pentane. The combined organic phase was washed with brine, dried over $\mathrm{MgSO}_{4}$, and filtered, and the solvent was evaporated under reduced pressure (ca. $1.333 \mathrm{kPa}$ ). The residue was purified by chromatography on silica gel (Merck Silicagel $60(0.063-0.200 \mathrm{~mm})$ for column chromatography (70-230 mesh ASTM)) eluted with $n$-pentane:EtOAc. The detailed experimental procedure, as well as the characterization of isolated compounds are provided in the Supporting Information.

\section{Preparation and characterization of isolated compounds}

Preparation and characterization of earlier published compounds (3a-k and $\mathbf{3} \mathbf{m - o}$ ) are presented in Supporting Information.

1-Phenyl-2-chloro-4-(trifluoromethyl)benzene (3 l) was prepared according to general procedure using $0.5 \mathrm{mmol}$ 2-chloro-1-iodo-4-(trifluoromethyl)benzene, $0.75 \mathrm{mmol}$

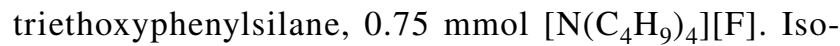
lated yield: $50 \% .{ }^{1} \mathrm{H}$ NMR $\left(250 \mathrm{MHz}, \mathrm{CDCl}_{3}\right): \delta(\mathrm{ppm})$ 7.42-7.51 (m, 5H), 7.51-7.54 (m, 1H), 7.56-7.65 (m, 1H), 7.76-7.83 (m, 1H). ${ }^{13} \mathrm{C}$ NMR $\left(62.9 \mathrm{MHz}, \mathrm{CDCl}_{3}\right) 123.8$ $(\mathrm{q}, \mathrm{J}=272 \mathrm{~Hz}), 124.1$ (q, J = 3.8 Hz), $127.4(\mathrm{q}, \mathrm{J}=3.8 \mathrm{~Hz})$, 
128.7, 128.8, 129.6, 131.3 (q, J = 33.4 Hz), 132.2, 133.6, 138.5. HRMS $[\mathrm{M}+\mathrm{H}]^{+}$Calculated: 257.0345, Measured: $257.0341(0.5 \mathrm{ppm})$.

\section{Results and discussion}

The applications of ionic liquids into the synthesis protocols have become into the focus of interest due to their versatility and tunability. However, it was shown that the number of chemical steps could be over 20 or even 30, reducing their impact towards green chemistry (Jessop 2011). Using a biomass-originated building block for the synthesis of an $\mathrm{IL}$, this number could be significantly reduced. It was shown that valerate-based ionic liquids could easily be synthesized from $\gamma$-valerolactone (Fegyverneki et al. 2010; Orha et al. 2018), which can be obtained by a two-step synthesis via valorization of lignocellulosic biomass wastes (Tukacs et al. 2014 and 2017).

To demonstrate their further applicability, they were first compared to the conventional 1-butyl-3-methylimidazolium cation-based ILs in the coupling of iodobenzene (1a) and triethoxyphenylsilane (2a) as a model reaction (Scheme 1) under typically used "Hiyama conditions" using tetrabutylammonium fluoride as $\mathrm{a} \mathrm{F}^{-}$source (Ismalaj et al. 2014). As with Sonogashira coupling in ILs (Orha et al. 2019), negligible conversion rates of 1a were detected in butylmethylimidazolium cation containing ILs (Table 1 entries 1-3). The reaction efficiency could be significantly increased by the introduction of tetrabutylphosphonium 4-ethoxyvalerate [TBP][4EtOV], resulting in the conversion of 1a. The product biphenyl (3a) was isolated with a yield of 58\% (Table 1, entry 6), which could be assumed to be higher by subsequent optimization of the reaction parameters.

The selection of a palladium source could have a significant effect on the efficiency of a catalytic transformation (Błaszczyk et al. 2009). When different precursors were compared, it was revealed that using of bis(triphenylphosphine)palladium(II) dichloride $\left(\mathrm{Pd}\left(\mathrm{PPh}_{3}\right)_{2} \mathrm{Cl}_{2}\right)$ and tris(dibenzylideneacetone)dipalladium $(0)\left(\mathrm{Pd}_{2}(\mathrm{dba})_{3}\right)$ gave acceptable yields of $\mathbf{3 a}$ (Table 2 , entries 1 and 5). A similar observation was reported for the Sonogashira reaction performed in biomass-originated ILs (Orha et al. 2019).

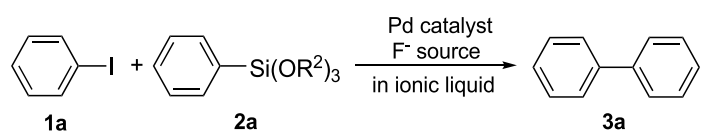

Scheme 1 Palladium-catalyzed Hiyama cross-coupling of iodobenzene (1a) and triethoxyphenylsilane (2a) in ionic liquid. $\mathrm{F}^{-}$source: TBAF
Table 1 Palladium-catalyzed Hiyama coupling reactions of iodobenzene (1a) and triethoxyphenylsilane (2a)

\begin{tabular}{lll}
\hline Entry & Ionic liquids & $\begin{array}{l}\text { Isolated } \\
\text { yield } \\
(\%)\end{array}$ \\
\hline 1 & {$[\mathrm{BMIM}]\left[\mathrm{PF}_{6}\right]$} & $<5$ \\
2 & {$[\mathrm{BMIM}]\left[\mathrm{BF}_{4}\right]$} & $<1$ \\
3 & {$[\mathrm{BMIM}][\mathrm{OctS}]$} & $<1$ \\
4 & {$[\mathrm{TEA}][4 \mathrm{HV}]$} & 10 \\
5 & {$[\mathrm{TBA}][4 \mathrm{HV}]$} & 8 \\
6 & {$[\mathrm{TBP}][4 \mathrm{EtOV}]$} & 58 \\
\hline
\end{tabular}

Reaction conditions: solvent $0.5 \mathrm{~mL}, 0.5 \mathrm{mmol}$ iodobenzene, 0.75 mmol triethoxyphenylsilane, $1 \mathrm{~mol} \% \mathrm{Pd}(\mathrm{OAc})_{2}, 1.5$ eq TBAF, $T=$ $130^{\circ} \mathrm{C}, t=24 \mathrm{~h}$

The residual moisture content could dramatically affect a transition-metal-catalyzed reaction. In this case, however, the fluoride activator $\left(\left[\mathrm{N}\left(\mathrm{C}_{4} \mathrm{H}_{9}\right)_{4}\right][\mathrm{F}]\right.$, hereafter TBAF) containing 3 eq water, the water content of the reaction mixtures was ca $10 \mathrm{~m} / \mathrm{m} \%$. It exceeds the typical residual water content of GVL-based ionic liquids (Strádi et al. 2015, Orha et al. 2018). Consequently, that, the protocol is hardly sensitive to water up to $10 \%$, can be assumed and no special handling of the reaction regarding the exclusion of air and moisture is necessary.

Generally, the organosilane activation with fluoride ion, that is, the formation of the pentavalent silicon center, is considered as a key step. In this way, a facile bond breaking of the carbon-silicon bond during transmetalation is favored. It was demonstrated that alkali metal salt such as $\mathrm{NaF}$ or CsF could also act as silane activators for Hiyama coupling reactions (Gurung et al. 2013; Monguchi et al. 2012). In addition, both ammonium- and phosphonium-based ionic liquid have been proved to be good extractants of Pd suggesting their complexing ability (Katsuta et al. 2011; RegelRosocka et al. 2015). Because of high water tolerance of

Table 2 Palladium-catalyzed Hiyama coupling reactions of iodoaromatic compounds with triethoxyphenylsilane

\begin{tabular}{lll}
\hline Entry & Catalyst precursor & $\begin{array}{l}\text { Isolated } \\
\text { yield } \\
(\%)\end{array}$ \\
\hline 1 & ${\mathrm{Pd}\left(\mathrm{PPh}_{3}\right)_{2} \mathrm{Cl}_{2}}_{2}$ & 70 \\
2 & $\mathrm{Pd}(\mathrm{OAc})_{2}$ & 58 \\
3 & $\mathrm{Pd}(\mathrm{cod}) \mathrm{Cl}_{2}$ & 45 \\
4 & $\mathrm{Pd}(\mathrm{dba})_{2}$ & 64 \\
5 & $\mathrm{Pd}_{2}(\mathrm{dba})_{3}$ & 76 \\
\hline
\end{tabular}

Reaction conditions: [TBP][4EtOV] solvent $0.5 \mathrm{~mL}, 0.5 \mathrm{mmol}$ iodobenzene, $0.75 \mathrm{mmol}$ triethoxyphenylsilane, $1 \mathrm{~mol} \%$ catalyst, $1.5 \mathrm{eq}$ TBAF, $T=130^{\circ} \mathrm{C}, t=24 \mathrm{~h}$

$d b a$ benzylideneacetone, cod: 1,5-cyclooctadiene, $O A c$ acetate 
the catalytic reactions, we attempt to convert $\mathbf{1 a}$ and $\mathbf{2}$ to $\mathbf{3}$ by the use of cheaper $\mathrm{NaF}$ in the presence of the different amount of water. However, no conversion was detected up to $20 \mathrm{wt} \%$ water. When $30 \mathrm{wt} \%$ of water loading was applied, moderate (39\%) conversion of 1a to 3a was detected in the presence of 2 eqv $\mathrm{NaF}$, even higher activator concentration at $130{ }^{\circ} \mathrm{C}$ for $24 \mathrm{~h}$. To conclude, the fluoride activator cannot be eliminated from the system.

Hereafter, to facilitate $\mathrm{C}-\mathrm{C}$ bond coupling involving several iodoaromatic substances (1a-o) and triethoxyphenylsilane (2), bis(triphenylphosphine)palladium(II) dichloride was selected as a catalyst precursor by the use of $1.5 \mathrm{eq}$ TBAF in the absence of any additional ligands and auxiliary base in [TBP][4EtOV] at $130{ }^{\circ} \mathrm{C}$ for $24 \mathrm{~h}$ (Table 3). It was demonstrated that the catalytic system generally could be utilized for the conversion of various iodoaromatic compounds. The substrate reactivity was not affected by the electronic parameters of the aromatic substrates. Thus, no Hammet-sigma $\left(\sigma_{p}\right)$ correlation can be established for para-substituted species. Both electron-donating groups, i.e., methyl, tert-butyl, methoxy (Table 3 entries 2-6), and electron-withdrawing groups, i.e., chloro, fluoro or trifluoromethoxy (Table 2, entries 7-12) were tolerated on the aryl iodide. No significant differences of the isolated yields were observed. Under identical conditions, iodopyridine derivatives and 2-iodothiophene were easily converted to the corresponding biphenyls $(\mathbf{3} \mathbf{~ m}-\mathbf{o})$. The conversion of 4-chloro-1-iodobenzene did not lead to the formation of 1,4-diphenylbenzene.

The GVL-based [TBP][4EtOV] ionic liquid has been proven as an excellent reaction media for transition-metalcatalyzed C-N (Ullmann type) (Orha et al. 2018) and C-C (Sonogashira) (Orha et al. 2019) coupling reactions previously. In the present work, we demonstrated that its utilization can be extended for Hiyama coupling, as well, which makes it an attractive biomass-based, environmentally friendly alternative for common, fossil-based solvents, and opens the possibility for its application in wider range of chemical transformations.

\section{Conclusions}

In conclusion, we have shown that tetrabutylphosphonium 4-ethoxyvalerate [TBP][4EtOV], a $\gamma$-valerolactone-based partially biomass-derived ionic liquid, can be applied as an alternative, safer reaction media for palladium-catalyzed Hiyama-type carbon-carbon bond-forming reactions of iodoaromatic compounds with triethoxyphenylsilane. A variety of biphenyl derivatives $(\mathbf{3 b}-\mathbf{l})$ and aromatic heterocycles ( 3 m-o) were obtained with $45-72 \%$ yield. The protocol that can be performed under air showed excellent tolerance to the moisture content of the reaction mixture.
Table 3 Palladium-catalyzed Hiyama coupling reactions of iodoaromatic compounds with triethoxyphenylsilane ${ }^{\mathrm{a}}$

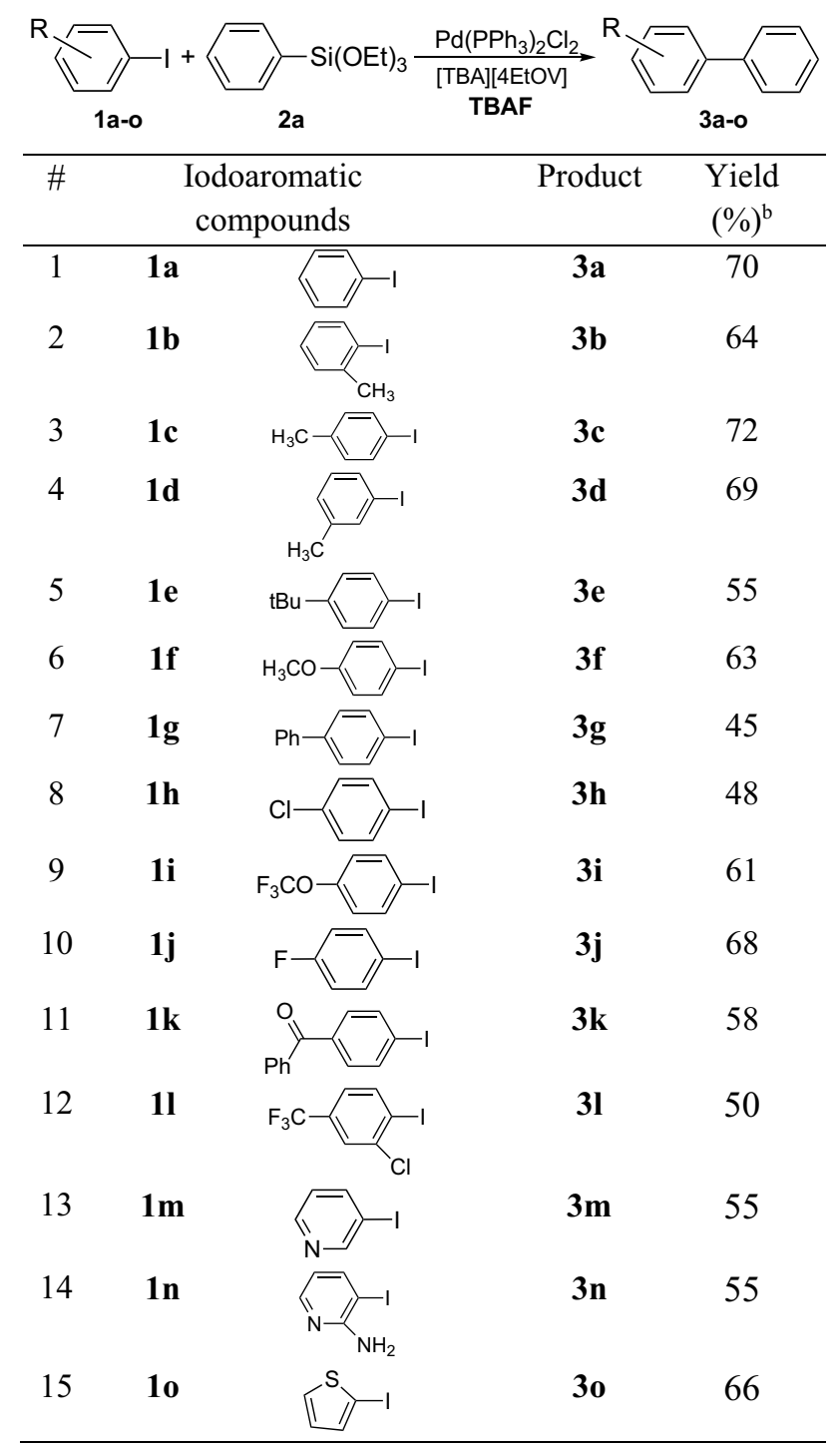

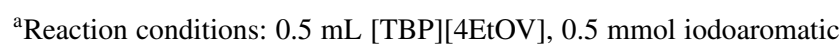
compounds, $0.75 \mathrm{mmol}$ triethoxyphenylsilane, $1.5 \mathrm{eq} \mathrm{TBAF}, \mathrm{T}=130$ ${ }^{\circ} \mathrm{C}, \mathrm{t}=24 \mathrm{~h}$

${ }^{\mathrm{b}}$ Isolated yield

Acknowledgements Open access funding provided by Budapest University of Technology and Economics. This work was funded by National Research, Development and Innovation Office under projects KH 129508 as well as Higher Education Excellence Program of the Ministry of Human Capacities in the frame of Biotechnology research area of Budapest University of Technology and Economics (BME FIKP-BIO).

\section{Compliance with ethical standards}

Conflict of interest On behalf of all authors, the corresponding author states that there is no conflict of interest. 
Open Access This article is licensed under a Creative Commons Attribution 4.0 International License, which permits use, sharing, adaptation, distribution and reproduction in any medium or format, as long as you give appropriate credit to the original author(s) and the source, provide a link to the Creative Commons licence, and indicate if changes were made. The images or other third party material in this article are included in the article's Creative Commons licence, unless indicated otherwise in a credit line to the material. If material is not included in the article's Creative Commons licence and your intended use is not permitted by statutory regulation or exceeds the permitted use, you will need to obtain permission directly from the copyright holder. To view a copy of this licence, visit http://creativecommons.org/licenses/by/4.0/.

\section{References}

Bäuerlein PS, Fairlamb IJS, Jarvis AG et al (2009) Ion-tagged $\pi$-acidic alkene ligands promote Pd-catalysed allyl-aryl couplings in an ionic liquid. Chem Commun 6:5734. https://doi.org/10.1039/ b906823f

Biajoli AFP, Schwalm CS, Limberger J et al (2014) Recent progress in the use of Pd-catalyzed $\mathrm{C}-\mathrm{C}$ cross-coupling reactions in the synthesis of pharmaceutical compounds. J Braz Chem Soc. https ://doi.org/10.5935/0103-5053.20140255

Błaszczyk I, Trzeciak AM, Ziółkowski JJ (2009) Catalytic activity of $\mathrm{Pd}(\mathrm{II})$ complexes with triphenylphosphito ligands in the sonogashira reaction in ionic liquid media. Catal Lett 133:262-266. https ://doi.org/10.1007/s10562-009-0181-y

CDER F (2017) Q3C - Tables and List Guidance for Industry. 1-10

Cheng K, Hu S, Zhao B et al (2013) Palladium-catalyzed hiyama-type cross-coupling reactions of arenesulfinates with organosilanes. J Org Chem 78:5022-5025. https://doi.org/10.1021/jo302791q

Denmark SE, Liu JHC (2010) Silicon-based cross-coupling reactions in the total synthesis of natural products. Angew Chem Int Ed 49:2978-2986. https://doi.org/10.1002/anie.200905657

Denmark SE, Regens CS (2008) Palladium-catalyzed cross-coupling reactions of organosilanols and their salts: practical alternatives to boron- and tin-based methods. Acc Chem Res 41:1486-1499. https://doi.org/10.1021/ar800037p

Denmark SE, Yang SM (2004) Total synthesis of (+)-brasilenyne. Application of an intramolecular silicon-assisted cross-coupling reaction. J Am Chem Soc 126:12432-12440. https://doi. org/10.1021/ja0466863

Denmark SE, Regens CS, Kobayashi T (2007) Total synthesis of papulacandin D. J Am Chem Soc 129:2774-2776. https://doi. org/10.1021/ja070071z

Denmark SE, Baird JD, Regens CS (2008) Palladium-catalyzed crosscoupling of five-membered heterocyclic silanolates. J Org Chem 73:1440-1455. https://doi.org/10.1021/jo7023784

Devendar P, Qu R-Y, Kang W-M et al (2018) Palladium-catalyzed cross-coupling reactions: a powerful tool for the synthesis of agrochemicals. J Agric Food Chem 66:8914-8934. https://doi. org/10.1021/acs.jafc.8b03792

Fegyverneki D, Orha L, Lang G, Horváth IT (2010) Gamma-valerolactone-based solvents. Tetrahedron 66:1078-1081. https://doi. org/10.1016/j.tet.2009.11.013

González-Sebastián L, Morales-Morales D (2019) Cross-coupling reactions catalysed by palladium pincer complexes. A review of recent advances. J Organomet Chem 893:39-51. https://doi. org/10.1016/j.jorganchem.2019.04.021

Gurung SK, Thapa S, Vangala AS, Giri R (2013) Copper-catalyzed Hiyama coupling of (hetero)aryltriethoxysilanes with (hetero) aryl iodides. Org Lett 15:5378-5381. https://doi.org/10.1021/ ol402701x
Hallett JP, Welton T (2011) Room-temperature ionic liquids: solvents for synthesis and catalysis. 2. Chem Rev 111:3508-3576. https:// doi.org/10.1021/cr1003248

Handy CJ, Manoso AS, McElroy WT et al (2005) Recent advances in siloxane-based aryl-aryl coupling reactions: focus on heteroaromatic systems. Tetrahedron 61:12201-12225. https://doi. org/10.1016/j.tet.2005.08.057

Hatanaka Y, Hiyama T (1988) Cross-coupling of organosilanes with organic halides mediated by a palladium catalyst and tris(diethylamino)sulfonium difluorotrimethylsilicate. J Org Chem 53:918-920. https://doi.org/10.1021/jo00239a056

Hirabayashi K, Kawashima J, Nishihara Y et al (1999) A new transformation of silanols. palladium-catalyzed cross-coupling with organic halides in the presence of silver(I) oxide. Org Lett 1:299 302. https://doi.org/10.1021/o1990614c

Horn KA (1995) Regio- and stereochemical aspects of the palladiumcatalyzed reactions of silanes. Chem Rev 95:1317-1350. https ://doi.org/10.1021/cr00037a009

Hosseinian A, Zare Fekri L, Monfared A et al (2018) Transitionmetal-catalyzed C-N cross-coupling reactions of N-unsubstituted sulfoximines: a review. J Sulfur Chem 39:674-698. https ://doi.org/10.1080/17415993.2018.1471142

Inés B, Moure MJ, SanMartin R et al (2011) "On-water" Hiyama coupling catalyzed by $\mathrm{CNC}$ pincer complexes of Pd(II). Arkivoc 2011:191-199. https://doi.org/10.3998/ark.5550190.0012.315

Ismalaj E, Strappaveccia G, Ballerini E et al (2014) $\gamma$-valerolactone as a renewable dipolar aprotic solvent deriving from biomass degradation for the hiyama reaction. ACS Sustain Chem Eng 2:2461-2464. https://doi.org/10.1021/sc5004727

Jana R, Pathak TP, Sigman MS (2011) Advances in transition metal $(\mathrm{Pd}, \mathrm{Ni}, \mathrm{Fe})$-catalyzed cross-coupling reactions using alkylorganometallics as reaction partners. Chem Rev 111:14171492. https://doi.org/10.1021/cr100327p

Jessop PG (2011) Searching for green solvents. Green Chem 13:1391-1398. https://doi.org/10.1039/c0gc00797h

Johansson Seechurn CCC, Kitching MO, Colacot TJ, Snieckus V (2012) Palladium-catalyzed cross-coupling: a historical contextual perspective to the 2010 nobel prize. Angew Chem Int Ed 51:5062-5085. https://doi.org/10.1002/anie.201107017

Katsuta S, Yoshimoto Y, Okai M et al (2011) Selective extraction of palladium and platinum from hydrochloric acid solutions by trioctylammonium-based mixed ionic liquids. Ind Eng Chem Res 50:12735-12740. https://doi.org/10.1021/ie201310v

Li J, Yang S, Wu W, Jiang H (2018) Recent advances in pd-catalyzed cross-coupling reaction in ionic liquids. Eur J Org Chem 2018:1284-1306. https://doi.org/10.1002/ejoc.201701509

Mandal B, Ghosh S, Basu B (2019) Task-specific properties and prospects of ionic liquids in cross-coupling reactions. Top Curr Chem. https://doi.org/10.1007/s41061-019-0255-2

Marset X, De Gea S, Guillena G, Ramón DJ (2018) NCN-pincer-Pd complex as catalyst for the hiyama reaction in biomass-derived solvents. ACS Sustain Chem Eng 6:5743-5748. https://doi. org/10.1021/acssuschemeng. 8 b00598

Miller ZD, Montgomery J (2014) Regioselective allene hydroarylation via one-pot allene hydrosilylation/pd-catalyzed crosscoupling. Org Lett 16:5486-5489. https://doi.org/10.1021/ol502 $766 \mathrm{q}$

Monguchi Y, Yanase T, Mori S, Sajiki H (2012) A practical protocol for the hiyama cross-coupling reaction catalyzed by palladium on carbon. Synthesis 45:40-44. https://doi.org/10.1055/s-0032-1316801

Nakao Y, Hiyama T (2011) Silicon-based cross-coupling reaction: an environmentally benign version. Chem Soc Rev 40:4893. https:// doi.org/10.1039/c1cs15122c

Orha L, Tukacs JM, Gyarmati B et al (2018) Modular synthesis of $\gamma$-valerolactone-based ionic liquids and their application as alternative media for copper-catalyzed Ullmann-type coupling 
reactions. ACS Sustain Chem Eng 6:5097-5104. https://doi. org/10.1021/acssuschemeng.7b04775

Orha L, Tukacs JM, Kollár L, Mika LT (2019) Palladium-catalyzed sonogashira coupling reactions in $\gamma$-valerolactone-based ionic liquids. Beilstein J Org Chem 15:2907-2913

Planellas M, Moglie Y, Alonso F et al (2014) Heck, sonogashira, and hiyama reactions catalyzed by palladium nanoparticles stabilized by tris-imidazolium salt. Eur J Org Chem 2014:3001-3008. https ://doi.org/10.1002/ejoc.201400162

Prechtl MHG, Scholten JD, Dupont J (2010) Carbon-carbon cross coupling reactions in ionic liquids catalysed by palladium metal nanoparticles. Molecules 15:3441-3461. https://doi.org/10.3390/ molecules 15053441

Premi C, Jain N (2013) Phosphane-free hiyama cross-coupling of aryl and heteroaryl halides catalyzed by palladium nanoparticles in ionic liquids. Eur J Org Chem 2013:5493-5499. https://doi. org/10.1002/ejoc.201300307

Ramgren SD, Garg NK (2014) Palladium-catalyzed acetylation of arenes. Org Lett 16:824-827. https://doi.org/10.1021/ol403570z

Regel-Rosocka M, Rzelewska M, Baczynska M et al (2015) Removal of palladium(ii) from aqueous chloride solutions with cyphos phoshonium ionic liquids as metal ion carriers for liquid-liquid extraction and transport across polymer inclusion membranes. Physicochem Probl Miner Process 51:621-631. https://doi.org/10.5277/ ppmp150221

Sakon A, Ii R, Hamasaka G et al (2017) Detailed mechanism for hiyama coupling reaction in water catalyzed by linear polystyrenestabilized pdo nanoparticles. Organometallics 36:1618-1622. https://doi.org/10.1021/acs.organomet.7b00170

Shi W, Liu C, Lei A (2011) Transition-metal catalyzed oxidative crosscoupling reactions to form $\mathrm{C}-\mathrm{C}$ bonds involving organometallic reagents as nucleophiles. Chem Soc Rev 40:2761. https://doi. org/10.1039/c0cs00125b

Sore HF, Galloway WRJD, Spring DR (2012) Palladium-catalysed cross-coupling of organosilicon reagents. Chem Soc Rev 41:1845-1866. https://doi.org/10.1039/C1CS15181A

Strádi A, Molnár M, Szakál P et al (2015) Catalytic transfer hydrogenation in $\gamma$-valerolactone-based ionic liquids. RSC Adv 5:7252972535. https://doi.org/10.1039/C5RA08297H

Tukacs JM, Novák M, Dibó G, Mika LT (2014) An improved catalytic system for the reduction of levulinic acid to $\gamma$-valerolactone. Catal Sci Technol 4:2908-2912. https://doi.org/10.1039/C4CY00719K

Tukacs JM, Holló AT, Rétfalvi N et al (2017) Microwave-assisted valorization of biowastes to levulinic acid. ChemistrySelect 2:13751380. https://doi.org/10.1002/slct.201700037

Wolf C, Lerebours R (2004) Palladium - Phosphinous acid-catalyzed $\mathrm{NaOH}$-promoted cross-coupling reactions of arylsiloxanes with aryl chlorides and bromides in water. Org Lett 6:1147-1150. https ://doi.org/10.1021/ol049851s

Yang Y, Lan J, You J (2017) Oxidative C-H/C-H coupling reactions between two (hetero)arenes. Chem Rev 117:8787-8863. https:// doi.org/10.1021/acs.chemrev.6b00567

Zhang P, Xu J, Gao Y et al (2014) Synthesis of diarylmethanes through palladium-catalyzed coupling of benzylic phosphates with arylsilanes. Synlett 25:2928-2932. https://doi. org/10.1055/s-0034-1379366

Publisher's Note Springer Nature remains neutral with regard to jurisdictional claims in published maps and institutional affiliations. 